\title{
PELATIHAN DAN PENGKADERAN PEMBUATAN WEB DESA AGAR WEB TIDAK PUNAH DI DESA GLAGAH KECAMATAN GLAGAH
}

\author{
Ulul ilmi $^{1}$, Ratna ${ }^{2}$ \\ Jurusan Teknik Elektro,Universitas Islam Lamongan ${ }^{1}$ \\ Jurusan Peternakan Fakultas Peternakan, Universitas Islam Lamongan ${ }^{2}$ \\ Jalan Veteran No 53A Lamongan \\ $\underline{\text { Ululilmi78@yahoo.co.id }}$, $\underline{\text { ratnakd@gmail.com }}^{2}$
}

\begin{abstract}
ABSTRAK
Beberapa tahun yang lalu desa glagah kecamatan glagah pernah dibuatkan web desa oleh mahasiswa KKN BBM Universitas Islam Lamongan. Namun karena pada saat itu tidak ada transfer keilmuan web dari mahasiswa KKN kepada perangkat desa, maka web desa menghilang seiring dengan berjalannya waktu.Untuk mengatasi persoalan ini, maka solusi yang ditawarkan untuk kegiatan KKN di desa Glagah tahun 2019 adalah melalui metode pelatihan dan pengkaderan pembuatan web bagi perangkat desa glagah.Diharapkan setelah mendapatkan pelatihan, web desa glagah tetap eksis, walaupun suatu saat akan ditinggalkan oleh mahasiswa KKN BBM ini.Hal ini bermakna setelah kegiatan KKN berakhir,diharapkan perangkat desa sudah memiliki keilmuan yang cukup tentang pembuatan web sehingga keberadaan web desa glagah tetap eksis sampai kapanpun. Dalam kegiatan pelatihan ini, web desa yang ditawarkan adalah berbasis domain gratis sehingga eksistensi web desa tetap eksis selamanya. Adapun web desa glagah sebelumnya masih berbasis domain berbayar sehingga setelah jangka waktu satu tahun hilang dengan sendiri nya.
\end{abstract}

Kata kunci : web, domain berbayar,domain gratis, pelatihan

\begin{abstract}
A few years ago the village of Glagah in the Glagah sub-district was once created a village web by students of the KKN BBM Lamongan Islamic University. But because at that time there was no web science transfer from KKN students to village officials, then the village web disappeared over time. To overcome this problem, the solution offered for KKN activities in Glagah village in 2019 was through training methods and cadre-making web for glagah village officials. It is hoped that after getting training, glagah village web will still exist, even though someday it will be abandoned by this KKN BBM student. This means that after the KKN activity ends, it is expected that the village apparatus already has sufficient knowledge about web creation so that the web the village of Glagah continues to exist forever. In this training activity, the village web offered is free domain-based so that the village web existence continues forever. As for Glagah village web, it was still based on a paid domain, so that after a period of one year, it disappeared on its own.
\end{abstract}

Keywords: web, paid domain, free domain, training

\section{PENDAHULUAN}

Dengan semakin bertambahnya tingkat kemajuan kehidupan manusia dan tingkat kemajuan teknologi, maka secara otomatis manusia harus berhadapan, bersinggungan, bersinergi dan menggunakan teknologi. Ada bermacam-macam teknologi seperti teknologi nuklir, teknologi 
ruang angkasa, serta teknologi web. Teknologi web adalah teknologi yang berhubungan dengan antarmuka untuk menjembatani server web dan klien mereka. Teknologi web mencakup bahasa markup, bahasa pemrograman, dan standar untuk mengidentifikasi dokumen serta tampilan. Kamu nggak perlu menjadi seorang jenius untuk bisa memahami teknologi web, kita hanya perlu memahami beberapa konsep-konsep dasar seperti memahami tentang berbagai aspek bahasa penerbitan web seperti HTML, ASP, JavaScript, CGI dan konfigurasi server.

Jendela browser juga termasuk dalam teknologi web, browser adalah sebuah jendela untuk melihat internet seperti sekarang kamu sedang melihat halaman ini, cara kerja web browser yaitu dengan menghubungkan internet melalui modem atau ISDN melalui server atau ISP untuk mesin remote, meminta dokumen/halaman tertentu kemudian memformat dokumen yang mereka terima untuk bisa dilihat di komputer.

Untuk melakukan hal ini, web browser menggunakan bahasa khusus yang disebut HTTP atau HyperText Transfer Protocol. Mesin remote yang berisi dokumen menjalankan server HTTP . Ketika server HTTP menerima permintaan halaman, ia akan mengirimkan kembali ke komputer lokal untuk melihatnya melalui browser.

Setiap dokumen di Web memiliki URL Uniform Resource Locator tertentu. Untuk memberitahu browser, server mana yang pergi ke untuk mendapatkan dokumen. HTTP menandakan bahwa bahasa yang akan digunakan adalah HyperText Transfer Protocol . Nama host adalah nama server. Misalnya, http://www.itnetwork.com akan mencari server IT Network.

HTML merupakan versi yang dapat diterima secara luas, termasuk dengan apa yang disebut Cascading Style Sheets (CSS). CSS memungkinkan pengembang web untuk menentukan banyak karakteristik yang berulang-ulang gaya (misalnya font, warna, dan spasi) dengan bagian tertentu dari kode HTML yang di sebut tag. Hal ini memungkinkan kecepatan, konsisten, dan dapat dlihat di seluruh situs. Sebuah organisasi yang disebut World Wide Web Consortium (W3C) mengembangkan standar HTML untuk memastikan bahwa mereka seragam di seluruh dunia. HTML terdiri dari teks, yang merupakan isi dari halaman web, dan tag, yang menentukan penampilan dan tata letak halaman tersebut.

Setiap dokumen terdiri dari kepala (ditandai dengan) dan tubuh (body) tag. Anda menggunakan taguntuk memberikan dokumen judul dan untuk menunjukkan parameter gaya lain bahwa browser harus menggunakan ketika menampilkan halaman. Terkait dengan 
HTML, XML adalah (Extensible Mark-up Language). XML merupakan meta-bahasa yang memungkinkan kamu untuk mengembangkan tag dokumen Anda sendiri.

Karena kebutuhan yang semakin meningkat untuk hiburan oleh komunitas web, beberapa bahasa bermunculan yang memungkinkan user untuk membawa animasi dan dinamisme ke halaman mereka. Ini termasuk CGI, JavaScript dan PHP. Yang pertama, CGI, digunakan untuk membuat aplikasi user-driven. CGI memungkinkan server web untuk berkomunikasi dengan program lain yang sudah berjalan di server. Hal ini memungkinkan halaman web yang akan dibuat 'on the fly' sesuai dengan data yang diberikan oleh user. Ini berarti bahwa kamu dapat membuat mesin pencari dan survei, menurut data yg diinput oleh user.

JavaScript adalah bahasa scripting berbasis obyek . Hal ini tertanam dalam versi terbaru dari browser populer dan memungkinkan untuk menjalankan executable dari browser. Ini berarti bahwa daripada menunggu halaman animasi untuk men-download dari server, animasi dapat dijalankan dari browser kamu, kemudian membuat konten HTML dinamis. JavaScript bekerja dengan browser kamu untuk mendeteksi dan bereaksi terhadap instruksi yang terjadi sebagai dokumen sedang dimuat, diberikan dan digunakan. Ini ditandai dalam HTML sebagai tag scripting.

Tidak seperti JavaScript, yang merupakan bahasa client -side, PHP adalah bahasa lintas server sisi platform yang scripting. Ini adalah cara untuk menempatkan instruksi dalam file HTML kamu untuk membuat konten dinamis. Web server kamu kemudian mengikuti petunjuknya. Hal ini terjadi sebelum halaman muncul di browser kamu. Program lain yang digunakan untuk membuat halaman web adalah Macromedia Flash dengan berbagai paket yang berbeda yang semuanya membuat/membentuk kode HTML. Flash adalah animasi suite yang memungkinkan pengguna untuk memutar animasi melalui browser mereka. Ini menciptakan bandwidth rendah efek multimedia dengan vektor dan grafis bitmap , gerak, audio MP3 dan form input.

Ada juga banyak WYSIWYG ( "Apa yang kamu lihat adalah apa yang kamu dapatkan") Halaman program editing yang memungkinkan orang-orang yang tidak memiliki keterampilan pemrograman bisa membuat halaman web dengan menyeret dan menjatuhkan elemen ( seperti kotak teks, dan gambar-gambar) ke halaman web. Program editing halaman WYSIWYG kemudian membuat kode HTML dan ekspor sebagai halaman melalui pengaturan publishing. 
Sedangkan Perancangan web ialah sekelompok keterampilan dan disiplin ilmu yang digunakan untuk membangun dan memelihara sebuah website. Disiplin ilmu dan keterampilan dalam bidang desain web meliputi 5 hal yaitu:

- $\quad$ Desain Grafis

Desain grafis ini berhubungan dengan bagaimana visualisasi grafis yang akan ditanamkan dalam sebuah website.

- Desain Interface

Dalam membuat web tak lepas dari bagaimana webiste bisa berinteraksi dengan baik dan optimal pada pengunjung web, untuk itu dibutuhkan tampilang yang rapih dan terstruktur agar informasi dapat tersampaikan dengan baik.

- Penyusunan Konten

Konten yg disuguhkan harus berkualitas dimulai dari penentuan topik dan penyusunan yang baik.

- $\quad$ Penulisan Kode

Sistem penyajian informasi harus bisa bekerja stabil dan maksimal, tanpa anda gangguan dan dapat digunakan pada kondisi yang dinamis.

Semakin berkembangnya internet di Indonesia, semakin banyak pula yang mengenal website. Website adalah apa yang Anda kunjungi setiap hari di internet.

Dari Google, Facebook, Twitter, CNN, Kompas, Tokopedia, Bukalapak, hingga Niagahoster. Ketika Anda membuka layanan-layanan tersebut di perangkat desktop atau mobile, yang Anda buka adalah website.

Website adalah sebuah kumpulan halaman pada suatu domain di internet yang dibuat dengan tujuan tertentu dan saling berhubungan serta dapat diakses secara luas melalui halaman depan (home page) menggunakan sebuah browser dan terdiri dari URL.

Sebagai contoh, untuk alamat website Niagahoster adalah https://www.niagahoster.co.id, jika diakses maka akan tampil home page seperti gambar di bawah. Sedangkan untuk halaman web adalah bagian yang diberi tanda kotak berwarna merah.

Ketika diklik akan mengarah ke halaman baru berupa informasi yang berbeda dengan home page. Website pertama kali dibuat oleh Tim Berners-Lee pada akhir 1980an dan baru resmi online pada tahun 1991.Tujuan awal Tim Berners-Lee membuat sebuah website adalah supaya lebih memudahkan para peneliti di tempatnya bekerja ketika akan bertukar atau melakukan perubahan informasi. 
Jika Anda ingin mengetahui seperti apa tampilannya, silakan akses tautan berikut http://info.cern.ch/. Pada saat itu, website mulai dapat digunakan secara gratis oleh publik baru diumumkan oleh CERN tepatnya tanggal 30 April 1993.

Website dapat dimiliki oleh individu, organisasi, atau perusahaan. Pada umumnya sebuah website akan menampilkan informasi atau satu topik tertentu, meskipun saat ini banyak website yang menampilkan berbagai informasi dengan topik yang berbeda.

Terdapat 3 unsur yang sangat vital pada website. Tanpa adanya semua unsur ini, website anda tidak akan pernah ditemukan dan diakses oleh pengguna di internet. Ketiga unsur yang dimaksud adalah:

1. Domain. Jika website diibaratkan sebagai produk, maka domain adalah merk. Penggunaan domain yang menarik akan membuat orang tertarik untuk memasuki suatu website. Dengan pemilihan nama domain yang unik juga membuat orang mudah mengingatnya untuk nantinya dikunjungi kembali.

2. Hosting. Tidak kalah pentingnya dengan domain, hosting memiliki peran untuk menyimpan semua database (script, gambar, video, teks dan lain sebagainya) yang diperlukan untuk membentuk suatu website. Banyak sekali penyedia jasa hosting di Indonesia, salah satunya Niagahoster yang menyediakan hosting terbaik untuk kecepatan akses website Anda.

3. Konten. Tanpa adanya konten pada website, maka website bisa dikatakan tidak memiliki tujuan yang jelas. Konten pada website dapat berupa teks, gambar atau video. Jika dilihat dari konten yang disuguhkan, terdapat beberapa macam website. Misalnya saja, sosial media, website berita, website jual beli atau website yang berisi konten yang berdasarkan minat, bakat serta hobi.

4. Website merupakan media untuk menampilkan informasi. Awal kemunculannya, informasi yang ditampilkan pada website hanya berupa tulisan.

5. Saat ini berbagai jenis website dapat Anda temukan dengan mudah, tidak hanya menampilkan informasi berupa tulisan saja.

Saat ini tersedia berbagai layanan yang dapat Anda gunakan untuk membuat website pribadi. Mulai dari yang gratis sampai layanan berbayar. Untuk yang gratis, Anda harus bersedia memiliki alamat website seperti www.namalayanan.com/username anda atau www.namawebsite.blogspot.com. Alamat website seperti contoh di atas tidak disarankan untuk Anda yang ingin memiliki konten lengkap, seperti dengan adanya video dan 
banyak gambar. Biasanya, penyedia layanan website gratis akan memberikan resource yang terbatas.

Selain itu, untuk alamat dari website Anda akan sulit bersaing di mesin pencari. Oleh karena itu kami menyarankan Anda untuk membuat website melalui layanan penyedia domain dan hosting.

Sehingga Anda dapat membuat website yang lebih profesional dengan alamat www.namaanda.com.

Website memiliki banyak manfaat di kehidupan kita. Anda bisa mengakses media sosial menggunakan website. Belanja online juga terjadi di website. Ketika Anda membutuhkan informasi penting, Anda juga bisa mengaksesnya melalui website.

Manfaat website tidak hanya itu, masih banyak manfaat yang bisa Anda dapatkan dari website. Berikut adalah beberapa manfaat website yang penting untuk Anda ketahui:

\section{Bangun Personal Branding}

Dimulai dari manfaat website untuk pribadi, yaitu website untuk personal branding. Dengan website Anda bisa membangun personal branding yang kuat dan terpercaya.Anda bisa membagikan hasil karya dan portfolio Anda di website. Baik itu tulisan, foto, lukisan, gambar, desain grafis, hingga musik. Anda bisa membangun personal branding yang profesional menggunakan website.

\section{Berbagi Cerita dan Informasi}

Sudah pernah baca cerita dari Raditya Dika? Atau Mungkin Anda pernah membaca kisah perjalanan Trinity Traveler. Mereka berdua adalah contoh blogger yang sukses bermodalkan cerita melalui website.

Anda pun bisa mengikuti jejak mereka dengan mulai membuat blog. Dengan membuat blog Anda bisa berbagi cerita atau informasi apa saja. Dari traveling, parenting, teknologi, keuangan, hingga kuliner.

\section{Menghasilkan Uang}

Ada banyak cara untuk menghasilkan uang menggunakan website. Anda bisa menjadi blogger dan mendapatkan banyak endorsement atau tawaran kerja sama. Selain itu, Anda juga bisa mendaftarkan website ke Google AdSense untuk mendapatkan uang dari iklan Google. Anda juga bisa mengikuti program affiliate marketing untuk menghasilkan uang dari website. Tugas Anda sebagai affiliate marketer adalah mempromosikan produk atau jasa dari 
perusahaan lain di website Anda. Kemudian Anda bisa mendapatkan komisi jika Anda yang membeli melalui website Anda.

Cara lain untuk menghasilkan uang melalui website adalah dengan membuat toko online. Anda bisa menjual berbagai produk atau jasa di website toko online Anda.

Membuat website tidak sesulit yang Anda bayangkan. Anda tidak perlu menjadi developer atau programmer untuk bisa membuat website. Kini Anda bisa membuat website tanpa perlu pengetahuan coding sama sekali?

Bagaimana caranya?

Caranya adalah dengan menggunakan WordPress. WordPress adalah platform pembuatan website yang memungkinkan Anda membuat website dalam hitungan menit saja. Dengan WordPress Anda bisa membuat website berkualitas tinggi tanpa harus berurusan dengan coding. Cukup menginstall WordPress, membeli hosting, pilih tema kesukaan Anda, install plugin penting, dan website sudah jadi.

Seperti yang sudah disebutkan di atas, website memiliki banyak manfaat. Baik itu untuk kepentingan pribadi atau bisnis. Anda bisa membuat website pribadi atau blog untuk membagikan cerita atau portfolio Anda.

Jika Anda ingin menghasilkan uang secara online, website adalah platform yang paling tepat. Anda bisa membuat website untuk menjual produk atau jasa secara online.

Intinya, apa pun yang ingin Anda raih secara online, website adalah solusinya. Jadi tunggu apa lagi? Mulai kesuksesan online Anda dengan membuat website.

Untuk membuat website diperlukan pengetahuan tentang bahasa pemrograman.

Bahasa pemrograman dikenal juga dengan nama bahasa komputer atau bahasa pemrograman komputer. Bahasa pemrograman adalah kumpulan sintaks yang berfungsi untuk memerintahkan perangkat lunak pada komputer. Secara singkat, bahasa pemrograman dipakai untuk membuat program komputer menggunakan aturan logika komputer.

Perkembangan teknologi pada saat ini mendorong banyak orang untuk mempelajari jenis bahasa pemrograman. Salah satu tujuannya adalah untuk mengenalkan website mereka melalui internet.

Sampai saat ini setidaknya sudah ada lebih dari 600 bahasa komputer di dunia. Bukan tidak mungkin seluruh bahasa komputer ini Anda kuasai. Hanya saja, biasanya seorang programmer tidak menggunakan semua bahasa komputer yang ada. Suatu proyek umumnya 
hanya menggunakan beberapa bahasa komputer, terkadang dikombinasikan dengan satu atau dua bahasa komputer lain.

\section{Mengapa Anda Sebaiknya Belajar Bahasa Pemrograman?}

Saat ini terdapat banyak agensi atau pengembang yang menyediakan layanan website instan. Layanan ini tentu memudahkan seseorang yang tidak mengetahui bahasa pemrograman sama sekali untuk membuat website. Meskipun mudah, akan tetapi tidak semua hal dapat dilakukan tanpa mengerti tentang bahasa pemrograman komputer. Jadi sangat perlu untuk mengerti, paling tidak sedikit mengenai pemrograman komputer.

Terkadang ada beberapa pengaturan yang membutuhkan kemampuan pemrograman. Misalnya, mengubah beberapa baris kode sehingga tampilan sesuai dengan apa yang diinginkan pengguna. Beberapa kasus, ini akan membutuhkan kemampuan pemrograman sehingga tampilan dapat disesuaikan dengan apa yang diinginkan.

Sedangkan jika membuat website sendiri menggunakan bahasa pemrograman website yang dikuasai, tentunya akan memberikan keleluasaan untuk menyesuaikan tampilan dengan apa yang diinginkan.

\section{Contoh Bahasa Pemrograman Untuk Website}

Hal penting yang perlu diperhatikan dalam pembuatan website adalah bahasa pemrograman yang digunakan. Menentukan bahasa komputer yang digunakan dapat dilakukan dengan mengetahui apa saja kebutuhan website yang ingin dikembangkan. Bahasa pemrograman yang digunakan dapat membantu menghasilkan situs yang sesuai dengan kebutuhan bisnis yang sedang Anda kembangkan.

Jika ingin membuat website tentu saja membutuhkan pengetahuan mengenai bahasa pemrograman. Website terbuat dari baris-baris kode yag menjadi sebuah file. Setiap file terhubung dengan file yang lainnya melalui fungsi yang sudah dideklarasikan didalamnya.

Pemrograman website terkenal dengan MVC yaitu model, view, controller yang memisahkan proses pada pengembangan website.

Secara umum ada beberapa fungsi utama dari sebuah bahasa pemrograman, yaitu :

1. Sebagai media komunikasi antara operator dengan mesin

2. Sebagai media mengoperasikan sebuah mesin

3. Sebagai media bagi programmer dalam mengembangkan sebuah aplikasi

4. Memberikan perintah kepada mesin dan komputer 
Meskipun ada banyak sekali bahasa pemrograman yang saat ini ada di dunia, apa saja bahasa pemrograman yang banyak digunakan para pengembang untuk membuat website mereka?

Berikut ini adalah bahasa pemrograman yang banyak dicari di Google dan PYPL PopularitY of Programming Language sebagai bahasa pemrograman untuk membuat website:

\section{Bahasa Pemrograman Java}

Fungsi bahasa pemrograman java tidak hanya untuk membuat aplikasi desktop, namun juga digunakan untuk membuat aplikasi mobile. Java merupakan bahasa pemrograman website yang paling populer tahun 2018. Persentase pencarian sebesar $22.62 \%$ dari total pencarian yang dilakukan pada Google.

Java merupakan bahasa pemrograman yang dikembangkan pada tahun 1991. Logo yang digunakan menggambarkan kopi yang diseduh. Sejak tanggal 23 Mei 1995 dirilis, bahasa pemrograman Java langsung naik dan menjadi bahasa pemrograman favorit. Java memberikan nuansa baru dalam perkembangan teknologi informasi. Ditambah, pada saat itu Sun memberikan source code Java secara cuma-cuma melalui internet. Kekuatan open source membuat bahasa pemrograman Java mudah berkembang dan dikenal oleh banyak pengembang. Oleh karena itu Java adalah salah satu bahasa pemrograman yang wajib dikuasai.

Hingga saat ini Java menjadi bahasa pemrograman yang hampir setiap pengembang mengetahui atau bahkan pernah menggunakannya. Selain digunakan sebagai bahasa pemrograman website, Java dbanyak dimanfaatkan untuk membuat aplikasi desktop maupun mobile.

\section{Bahasa Pemrograman Python}

Python dikembangkan oleh Guido van Rossum pada tahun 1990 di Stichting Mathematisch Centrum (CWI), Amsterdam sebagai kelanjutan dari bahasa pemrograman ABC. Python banyak digunakan oleh perusahaan besar dalam pengembangannya seperti NASA, Instragam, Google, Yahoo, Reddit, dan juga situs streaming video populer YouTube. Jika dikategorikan dalam tingkatan bahasa komputer, Pyhton tergolong ke dalam bahasa pemrograman tingkat tinggi. Sama seperti Java, fungsi bahasa pemrograman Phyton ini bisa untuk membangun aplikasi dari website dan mobile.

Popularitas Python sebesar 22.05\% dari total responden berdasarkan pencarian yang dilakukan pada Google Search dan cenderung meningkat. Jika dilihat dari pengguna 
Facebook, di Indonesia terdapat grup khusus membahas bahasa Python dan sudah lebih dari 23.000 akun yang bergabung.

Jika Anda baru memulai belajar tentang pemrograman, Python termasuk bahasa yang cukup mudah untuk dipelajari. Selain itu masih banyak kelebihnya seperti, sintaks yang digunakan cukup sederhana. Pemuatan kembali secara dinamis modul phyton seperti memodifikasi aplikasi tanpa menghentikannya.

Meskipun mempunyai banyak kelebihan, masih ada beberapa kekurangan Python yang mungkin akan sedikit menyulitkan, seperti beberapa penugasan terdapat diluar dari jangkauan python, seperti bahasa pemrograman dinamis lainnya, Python tidak secepat atau efisien sebagai statis, tidak seperti bahasa pemrograman kompilasi seperti bahasa C.

\section{Bahasa Pemrograman Javascript}

Sejarah JavaScript dimulai sekitar tahun 1994, ketika internet dan website sedang mengalami perkembangan yang pesat. Website pada saat itu umumnya dibuat menggunakan bahasa pemograman PERL yang pemrosesannya hanya bisa dilakukan di sisi web server. Javascript menempati urutan ketiga dengan persentase pencarian $8.56 \%$ setelah Python. Fungsi bahasa pemrograman Javascript termasuk istimewa menurut saya, karena mampu mengembangkan website yang menarik dan interaktif. Maka banyak saat ini banyak website yang menggunakan Javascript pada kode program di dalamnya. Tidak mengherankan, karena Javascript pada awalnya memang dikembangkan dengan tujuan untuk membuat sebuah website.

Sedangkan Netscape menjadi perusahaan teknologi yang beruntung dapat mengembangkan Javascript dan berguna untuk banyak pengembang sampai dengan saat ini. Tidak hanya digunakan untuk membuat website, penggunaan JavaScript juga mengarah ke pengembangan aplikasi mobile, game, dan desktop. Jadi tentunya JavaScript menjadi bahasa pemrograman yang populer dan tidak asing dikalangan pengembang website.

Kelebihan Javascript seperti tidak membutuhkan resource memory besar (ringan dan kecil), tidak membutuhkan resource memory besar (ringan dan kecil), dinamis, dan mudah untuk dikembangkan.

Sedangkan untuk kekurangannya adalah script yang digunakan pada Javascript tidak terenkripsi, bukan untuk pengembangan aplikasi stand alone, dan memiliki keterbatasan objek. CSS dan HTML juga merupakan bahasa pemrograman yang wajib diketahui oleh 
pengembang website. Ada tiga bahasa komputer yang wajib diketahui oleh pengembang website yaitu Javascript, CSS, dan HTML.

\section{Bahasa Pemrograman PHP}

Popularitas PHP sebagai bahasa pemrograman untuk website sebesar $8.22 \%$ pada pencarian di Google Search dan lebih dari 10 juta website di dunia sudah menggunakan bahasa ini.

Sejak dikembangkan pada tahun 1994, PHP menjadi bahasa komputer yang populer untuk mengembangkan website. Banyak website besar menggunakan bahasa ini sebagai salah satu komponennya. Sebagai contoh Content Management System (CMS) seperti WordPress dan Joomla dibuat dengan bahasa pemrograman dasar PHP. Facebook dan Wikipedia juga menjadi salah satu penggunanya.

Bahasa pemrograman PHP adalah sebuah bahasa script yang tidak melakukan sebuah kompilasi dalam penggunaannya. Web Server yang mendukung PHP dapat ditemukan dimana-mana dari mulai apache, IIS, Lighttpd, hingga Xitami dengan konfigurasi yang relatif mudah. Dalam sisi pengembangan lebih mudah, karena banyaknya milis-milis dan developer yang siap membantu dalam pengembangan.

PHP memiliki kelemahan security tertentu apabila programmer tidak jeli dalam melakukan pemrograman dan kurang memperhatikan isu dan konfigurasi PHP. Tidak ideal untuk pengembangan skala besar. Berbeda dengan java, fungsi bahasa pemrograman ini tidak memiliki sistem pemrograman berorientasi objek yang sesungguhnya (sampai versi 4 ini). Tidak bisa memisahkan antara tampilan dengan logik dengan baik (walau penggunaan template dapat memperbaikinya).

\section{METODE}

Metode yang digunakan dalam penelitian ini adalah metode eksperimen. Metode eksperimen dalam penelitian ini adalah dalam bentuk pelatihan dan pengkaderan dalam pembuatan web desa glagah.Diharapkan dengan adanya metode eksperimen, perangkat desa memiliki kemampuan untuk berlatih membuat web desa secara mandiri sehingga ketika kegiatan KKM BBM 2019 berakhir, perangkat desa sudah memiliki kemampuan untuk membuat dan menjalankan web desa. 


\section{HASIL DAN PEMBAHASAN}

Hasil yang dicapai dalam penelitian ini adalah perangkat desa mendapatkan informasi, pengetahuan dan skill tentang bagaimana cara membuat web desa. Hasil yang dicapai ditunjukkan pada gambar berikut .

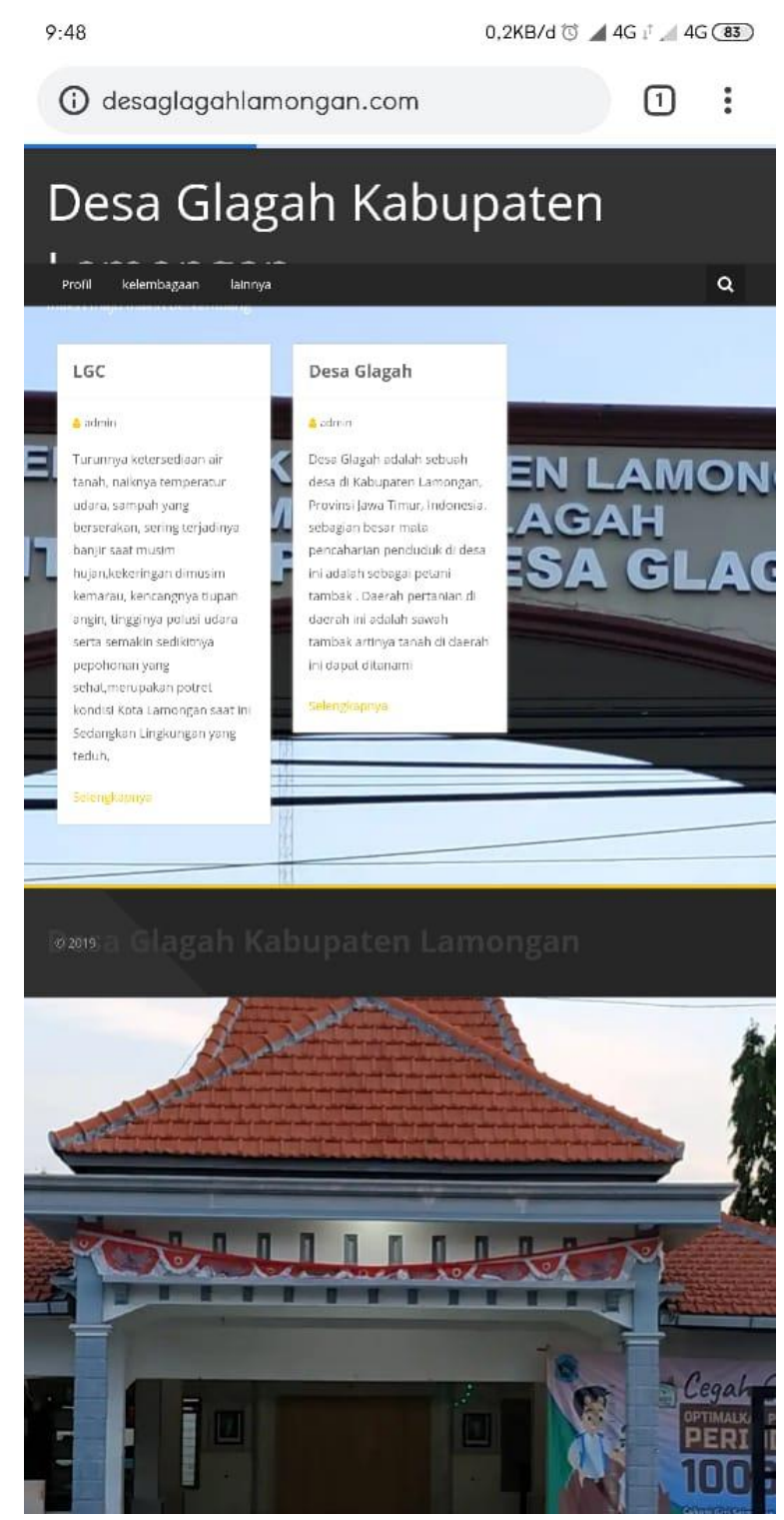

\section{Gambar 1}

Dengan adanya hasil ini maka tujuan dari penelitian ini telah tercapai dan sekaligus untuk menjawab permasalahan yang ada. 


\section{SIMPULAN}

Berdasarkan hasil ini, maka kegiatan kuliah kerja nyata berbasis masyarakat (KKNBBM) 2019 telah mampu menjawab persoalan yang terdapat di dalam masyarakat desa glagah dalam bentuk mampu membuat web desa secara mandiri.

Adapun saran dari kegiatan KKN BBM adalah pembuatan web jangan hanya terfokus pada web desa saja, tetapi juga perlu difikirkan pembuatan web untuk karang taruna.

\section{DAFTAR PUSTAKA}

Akbar, Ali. 2005. Menguasai Internet Plus Pembuatan Web, M2S Bandung, Bandung.

Jasmadi. 2004. Koleksi Template Web dan Teknik Pembuatannya, Andi, Yogyakarta.

Nugroho, Bunafit. 2004. PHP dan MySQL dengan Editor Dreamweaver MX, Andi, Yogyakarta.

Nugroho, Bunafit. 2008. Latihan Membuat Aplikasi Web PHP dan MySQL dengan Dreamweaver $M X(6,7,2004)$ dan 8, Gava Media, Yogyakarta.

MADCOMS. 2004. Aplikasi Program PHP + MySQL untuk Membuat Website Interaktif, Andi, Yogyakarta.

Meissa, Indra. 2009. Bikin Web Asik Ala Joomla 1.5, GagasMedia, Jakarta. 